\title{
MFAP5 and TNNC1: Potential markers for predicting occult cervical lymphatic metastasis and prognosis in early stage tongue cancer
}

\author{
Xi Yang ${ }^{1}$, Kailiu Wu ${ }^{1}$, Siyi Li ${ }^{1}$, Longwei Hu${ }^{1}$, Jing Han ${ }^{1}$, Dongwang Zhu ${ }^{1}$, Xuerui \\ Tian $^{1}$, Wei Liu ${ }^{1}$, Zhen Tian ${ }^{2}$, Laiping Zhong ${ }^{1}$, Ming Yan ${ }^{1}$, Chenping Zhang ${ }^{1}$, Zhiyuan \\ Zhang $^{1}$ \\ ${ }^{1}$ Department of Oral \& Maxillofacial - Head \& Neck Oncology, Shanghai Key Laboratory of Stomatology, Shanghai Ninth \\ People's Hospital, Shanghai Jiaotong University School of Medicine, Shanghai 200011, China \\ ${ }^{2}$ Department of Oral Pathology, Shanghai Key Laboratory of Stomatology, Shanghai Ninth People's Hospital, Shanghai \\ Jiaotong University School of Medicine, Shanghai 200011, China \\ Correspondence to: Chenping Zhang, email: zhang.chenping@hotmail.com \\ Zhiyuan Zhang, email: zhangzy0502@qq.com \\ Keywords: potential marker, metastasis and prognosis, tongue cancer, microarray \\ Received: May 30, $2016 \quad$ Accepted: September 20, $2016 \quad$ Published: October 04, 2016
}

\section{ABSTRACT}

The purpose of this study is to identify candidate genes that could predict prognosis of early-stage tongue squamous cell carcinoma (TSCC) and its occult cervical lymphatic metastasis by large-scale gene expression profiling. Tumor tissue and matched normal mucosa samples were collected from patients with TSCC and analyzed with Affymetrix HTA2.0 high-density oligonucleotide array. Differentially expressed genes in TSCC with cervical lymph node metastasis (CLNM) were further analyzed with Gene Ontology and Kyoto Encyclopedia of Genes and Genomes for their functions and related pathways. A total of 107 differentially expressed genes ( $p$ $<0.05)$ were identified by microarray in TSCC samples with CLNM $(n=6)$ compared to those without CLNM $(n=6)$. Genes involved in the cell-matrix adherens junction and migration function including MFAP5, TNNC1, MGP, FBFBP1 and FBX032 were selected and validated by RT-PCR in TSCC samples $(n=32)$. Of the five genes, MFAP5 and TNCC1 expressions were further validated by immohistochemistry ( $n$ = 61). The significant positive correlation between MFAP5 and TNNC1 expression $(p<0.001)$ was observed. Notably, over-expression of MFAP5 and TNNC1 were correlated with CLNM, metastasis relapse-free survival and overall survival. Our findings indicated that MFAP5 and TNNC1 may be potential markers for predicting occult cervical lymphatic metastasis and prognosis of oral tongue carcinoma.

\section{INTRODUCTION}

Tongue squamous cell carcinoma (TSCC) is the most common cancer in the oral cavity $[1,2]$, and surgery is the preferred treatment for primary tumors in TSCC patients [3, 4]. Although these primary tumors may be well controlled by surgical resection, a neck dissection is necessary when there is evidence of lymph node metastasis $[5,6]$. However, there are no cancer cells in the cervical lymphatic tissues in some patients. Controversy exists in the selection of therapeutic strategy for TSCC, especially in $\mathrm{N}_{0}$ patients $[7,8]$. Selective neck dissection may be appropriate in such cases. However, this prophylactic strategy may lead to higher morbidity and economic costs [2]. Even if neck dissection is not included in the management of early-stage TSCC, the mortality of $\mathrm{N}_{0}$ patients with occult lymphatic metastasis may also significantly increase [9]. Due to the lack of accurate and reliable methods for predicting occult cervical lymphatic metastasis, it is difficult to make treatment decisions in TSCC patients. This underscores the need to identify potential markers that can predict occult cervical lymphatic metastasis and prognosis of patients with earlystage TSCC.

The cellular and molecular heterogeneity of TSCC and the large number of genes potentially involved in 
oral carcinogenesis and progression emphasize the importance of studying multiple gene alterations on a global scale [10]. Gene expression analysis has proved to be a useful tool for predicting clinical outcome in human malignant tumors including head and neck cancers [11-14]. It also allows us to classify individual cancers and to better understand the molecular pathogenesis of cancers [10].

In this study, high-density oligonucleotide array was used to generate a molecular portrait of TSCC and to examine the correlations between gene expression patterns and clinically relevant parameters. We performed hierarchical clustering analysis and analyzed gene expression profiles by comparing primary tumors at the same $\mathrm{T}_{2}$ and $\mathrm{N}_{0}$ stage and their matched normal mucosa. Clinically significant genes were identified based on lymph node status and tumor stage. Data from the microarray analysis were validated by RT-PCR and immunochemistry, in which the specimens were obtained from our clinical research about treatment strategy of early-stage tongue cancer. This study aimed to identify candidate genes that could predict occult cervical lymphatic metastasis and prognosis of patients with early-stage TSCC.

\section{RESULTS}

\section{Hierarchical clustering analysis}

Gene expression profiles of 12 TSCC patients were analyzed by 67,528 probes and the primary TSCC tumor samples were compared with their matched adjacent normal mucosa in the Affymetrix array. The clinical and pathological characteristics of all patients were shown in Supplementary Table S1. Clustering analyses were performed separately on (1) tumor samples and their matched normal tissue samples (TN paired, $n=12$ ) and (2) tumor samples in two groups with or without cervical lymph node metastasis (CLNM) ( $n=6$ in each group). The genetic differences between these two groups were shown in Figure 1A. We found 826 genes in patients with CLNM and 862 genes in patients without CLNM that could distinguish tumors from matched normal tissues. In addition, 107 genes and their probes were significantly altered in patients with CLNM, 14 of which could be applied as indicators of tumor.

Figure 1B showed the 107 genes that were upregulated or down-regulated along with the fold changes in gene expression, and Figure 2 showed the results of the GO functional analysis and the KEGG pathway analysis of these 107 genes. The pathways related to tight junction, focal adhesion, cell adhesion and cellmatrix adhesion were significantly altered in patients with CLNM. Therefore, genes involved in cell-matrix adherens junction and migration function (i.e., MFAP5, TNNC1, MGP, FBFBP1 and FBXO32) were selected for further analysis and validation.

\section{Quantitative real-time RT- PCR analysis}

Specimens were collected from patients with Stages II $\left(\mathrm{T}_{2} \mathrm{~N}_{0} \mathrm{M}_{0}\right)$ TSCC for further analysis. Regression analysis was performed to compare clinical and pathological characteristics of patients without cervical nodal metastasis $\left(\mathrm{N}_{0}\right)$ with those with nodal metastasis (Supplementary Table S2). We analyzed data from 12 patients whose tumor and matched normal mucosa were available for validating microarray results. Expressions of MFAP5, TNNC1, MGP, FBFBP1 and FBXO32 were analyzed in a larger cohort of 32 patients. We performed a two-step quantitative RT-PCR to validate expression changes identified by gene array analysis for the 5 selected genes in the 32 patients (Figure 3). Expressions of MFAP5 and TNNC1 were significantly elevated in $\mathrm{N}_{0}$ patients (MFAP5: $p=0.0034$; TNNC1: $p=0.0142$, respectively). FGFBP1 was also overexpressed, but with no significant difference between patients with and without CLNM ( $p=$ $0.1567)$.

\section{Immunohistochemistry of MFAP5 and TNNC1}

Immunohistochemistry was performed to further investigate MFAP5 and TNNC1 expressions at the protein level. A total of 61 TSCC patients were identified with adequate histological material for immunohistochemistry and sufficient clinical data for survival analysis. Of these 61 patients, 56 were positive for MFAP5 and 57 were positive for TNNC1 (Figure 4). Table 1 showed MFAP5 and TNNC1 expressions and scores in patients with different cervical lymphatic conditions.

\section{Survival analysis}

The overall survival was $65.785 \pm 2.902$ months in patients negative for MFAP5 $(n=24)$, and $50.929 \pm 3.840$ months in patients positive for MFAP5 $(n=37) ; 50.929$ \pm 3.840 months in patients negative for TNNC1 $(n=19)$, $54.619 \pm 3.782$ months in patients positive for TNNC1 $(n$ $=42) ; 62.929 \pm 3.923$ months in patients negative for both MFAP5 and TNNC1 (MFAP5- TNNC1-) $(n=14), 67.571$ \pm 2.340 months in patients positive for either MFAP5 or TNNC1 (MFAP5+TNNC1- or MFAP5-TNNC1+) $(n=$ $15)$, and $48.516 \pm 4.302$ months in patients positive for both MFAP5 and TNNC1 (MFAP5+TNNC1+) $(n=32)$, respectively (Figure 5A). The overall survival of patients and factors affecting prognosis were shown in Table 2.

\section{Correlation between MFAP5 and TNNC1 expressions}

There was a significant positive correlation between MFAP5 and TNNC1 expressions (Pearson correlation coefficient $=0.473, p<0.001)$.MFAP5 and TNNC1 expressions were associated with CLNM and cervical lymphatic recurrence. A large majority of patients with 
CLNM were positive for MFAP5 (11/13) and TNNC1 $(15 / 15)$ and had recurrence of TSCC. Positive MFAP5 and TNNC1 expressions were significantly related to TSCC recurrence ( $p=0.006$ and $p=0.004$, respectively; Table 3). Patients with positive MFAP5 expression had a disease-free survival of $48.380 \pm 4.428$ months, which was significantly shorter than that in patients with negative MFAP5 expression $(65.171 \pm 3.278$ months $)$.
To assess the influence of each factor, univariate and multivariate analysis was performed to assess which factors remained independent indicators of prognosis. On multivariate analysis, the adjusted HR for prognosis was 7.854 for co-expression of MFAP5 and TNNC1 expression. In addition, the prognostic factors of age( $\leq 60$ years $)$ and nerve vascular invasion was still significant, but inferior to prognostic of both proteins coexpression.(Table 4)

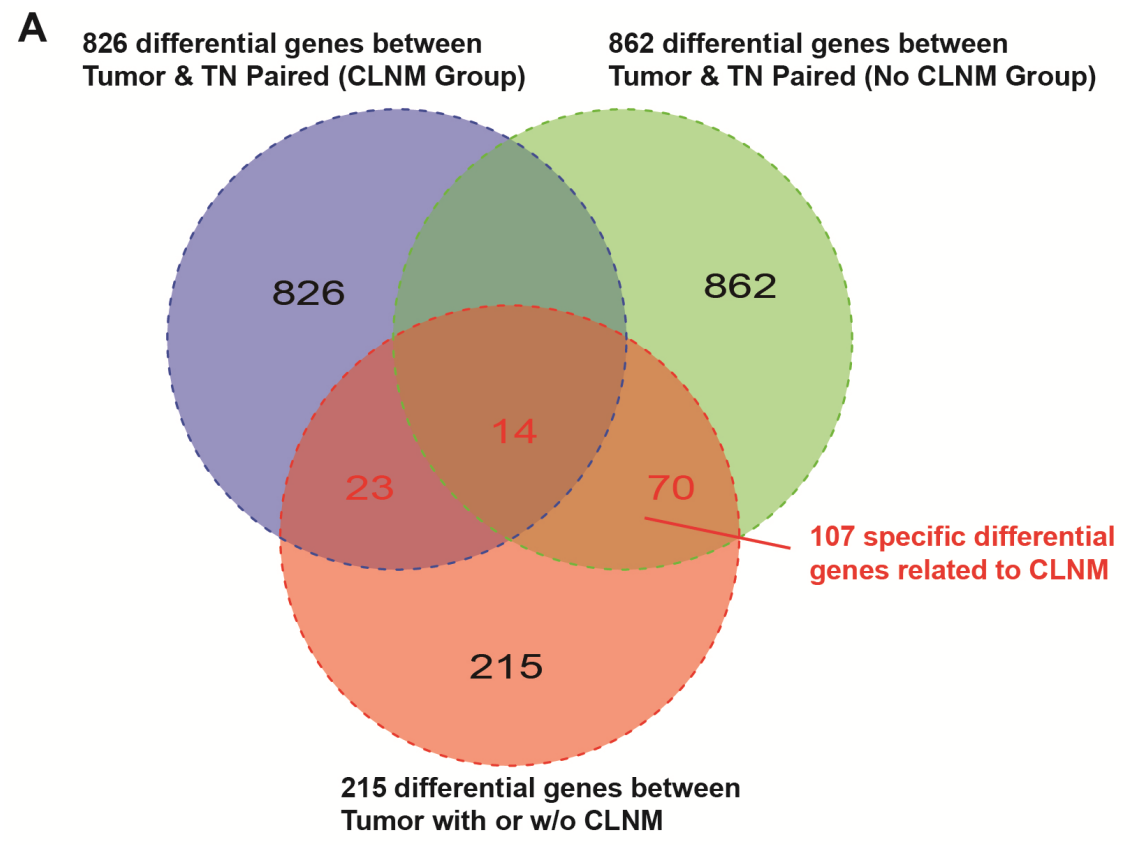

B

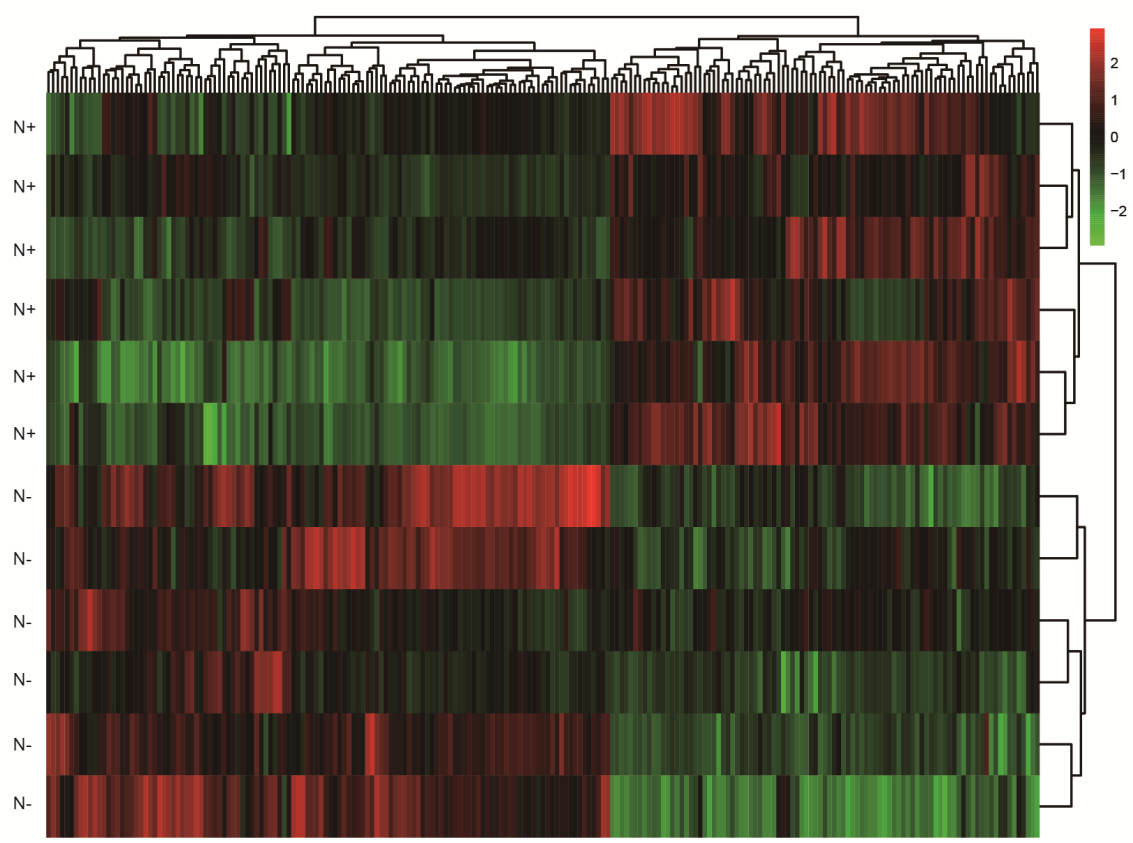

Figure 1: A. One hundred and seven differentially expressed genes in TSCC tissues with CLNM. Individual difference was removed by compassion of tumor tissues and matched normal tissues. B. Hierarchical clustering of gene expression data for TSCC with or without CLNM. It showed that 107 genes were up-regulated (red) or down-regulated (green) with over 2-fold change. C. MFAP5, TNNC1, MGP and other genes involved in cell adhesion, focal adhesion, cell-matrix adhesion and cell migration were present. 
A

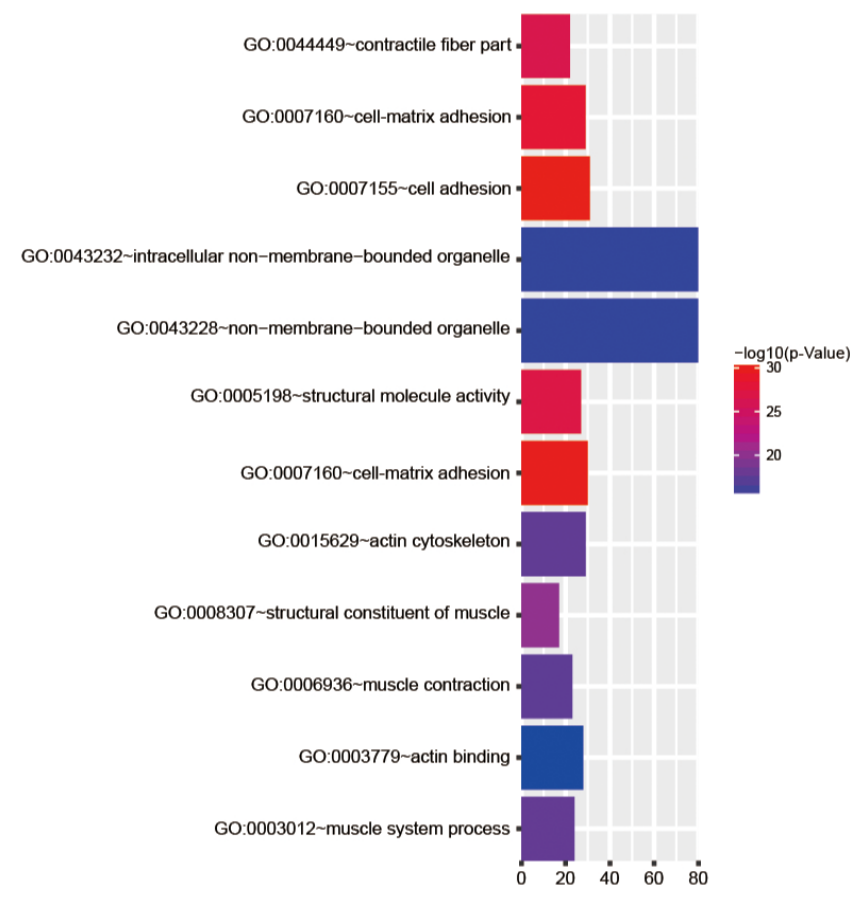

B

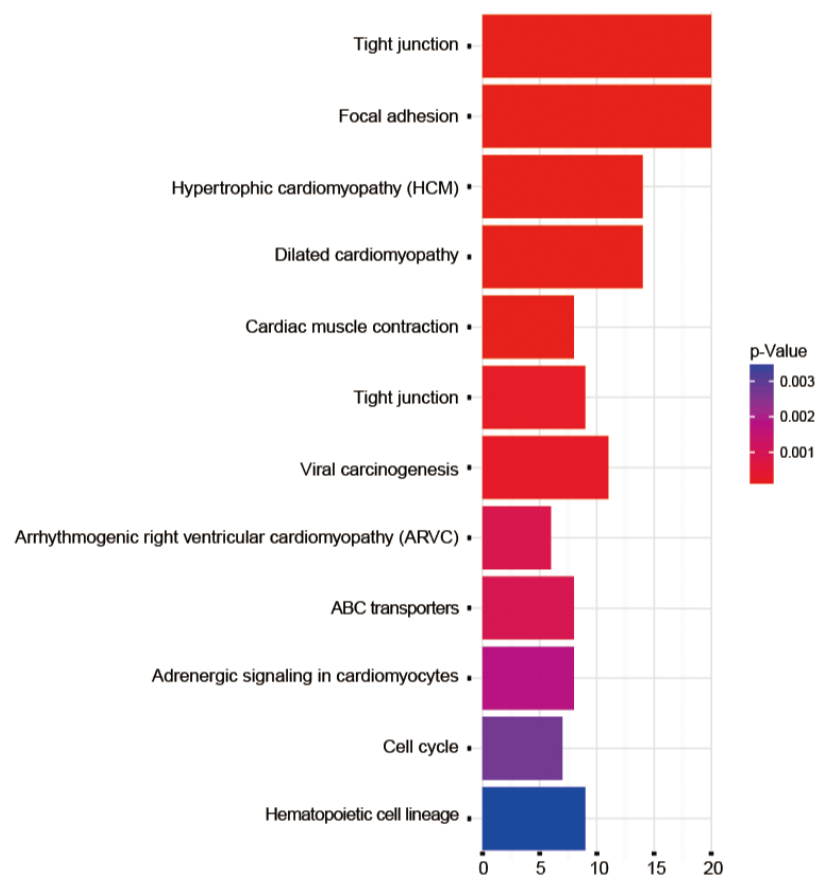

Figure 2: GO functional analysis and KEGG pathway analysis. The target genes are concentrated in A. 12 major GO terms and B. 12 major KEGG pathways.

A

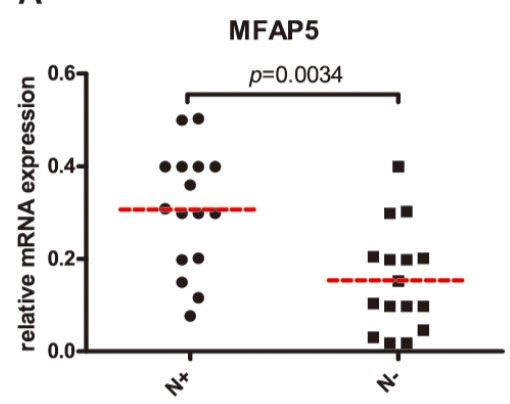

C

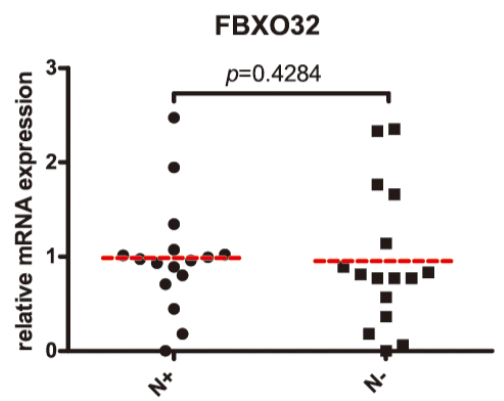

B

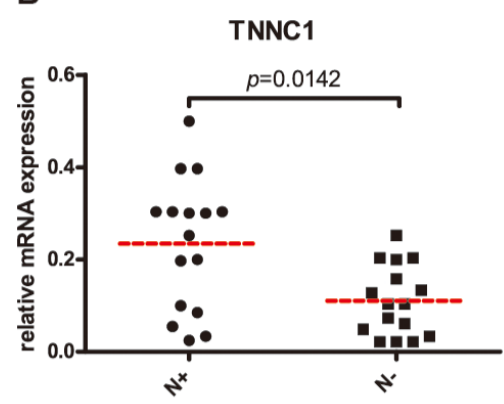

D

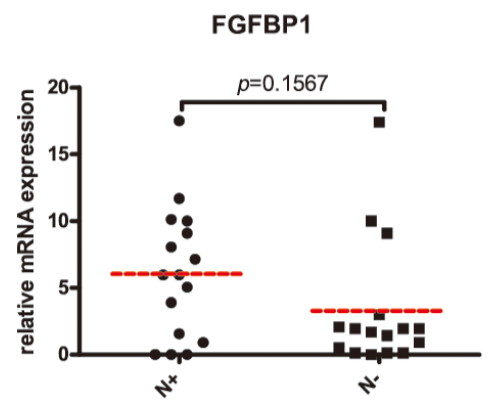

E

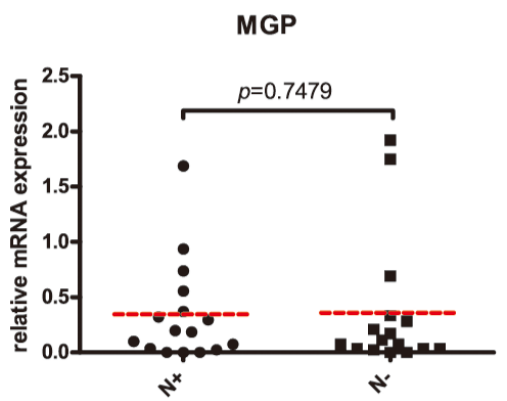

Figure 3: Quantitative comparison of MFAP5 (A), TNNC1 (B), FBXO32 (C), FGFBP1 (D) and MGP (E) mRNA expressions in 16 paired TSCC with or without occult CLNM. $P$ values were presented. N+: TSCC with occult CLNM; N-: TSCC without occult CLNM. 


\section{DISCUSSION}

Molecular biomarkers involved in the pathogenesis of head and neck cancers including oral cancer have long been a subject of intense research. Abnormal expressions of MAGED4B, KLK13, MMP9 and GLUT3 were correlated with CLNM $[10,15,16]$. However, TSCC at early stage and its occult cervical lymphatic metastasis have rarely been investigated. In clinical practice, it remains controversial whether selective neck dissection is needed in the treatment of TSCC, especially in patients with $\mathrm{cT}_{2} \mathrm{~N}_{0} \mathrm{M}_{0}$ tongue cancer. Thus, we performed transcriptome profiling of $\mathrm{cT}_{2}$ tongue cancer at the same TNM stage. One group had lymph node metastasis within the 6-month follow-up and another group had no metastasis in the following 18 months.

We have focused on adhesion molecules (including focal adhesion, junction adhesion, etc.) and cell migration based on the GO analysis and the KEGG analysis. MFAP5, TNNC1, MGP, FGFBP1 and FBXO32 genes were selected for validation using real-time PCR. Some molecules, like ZEB1, which played an important part
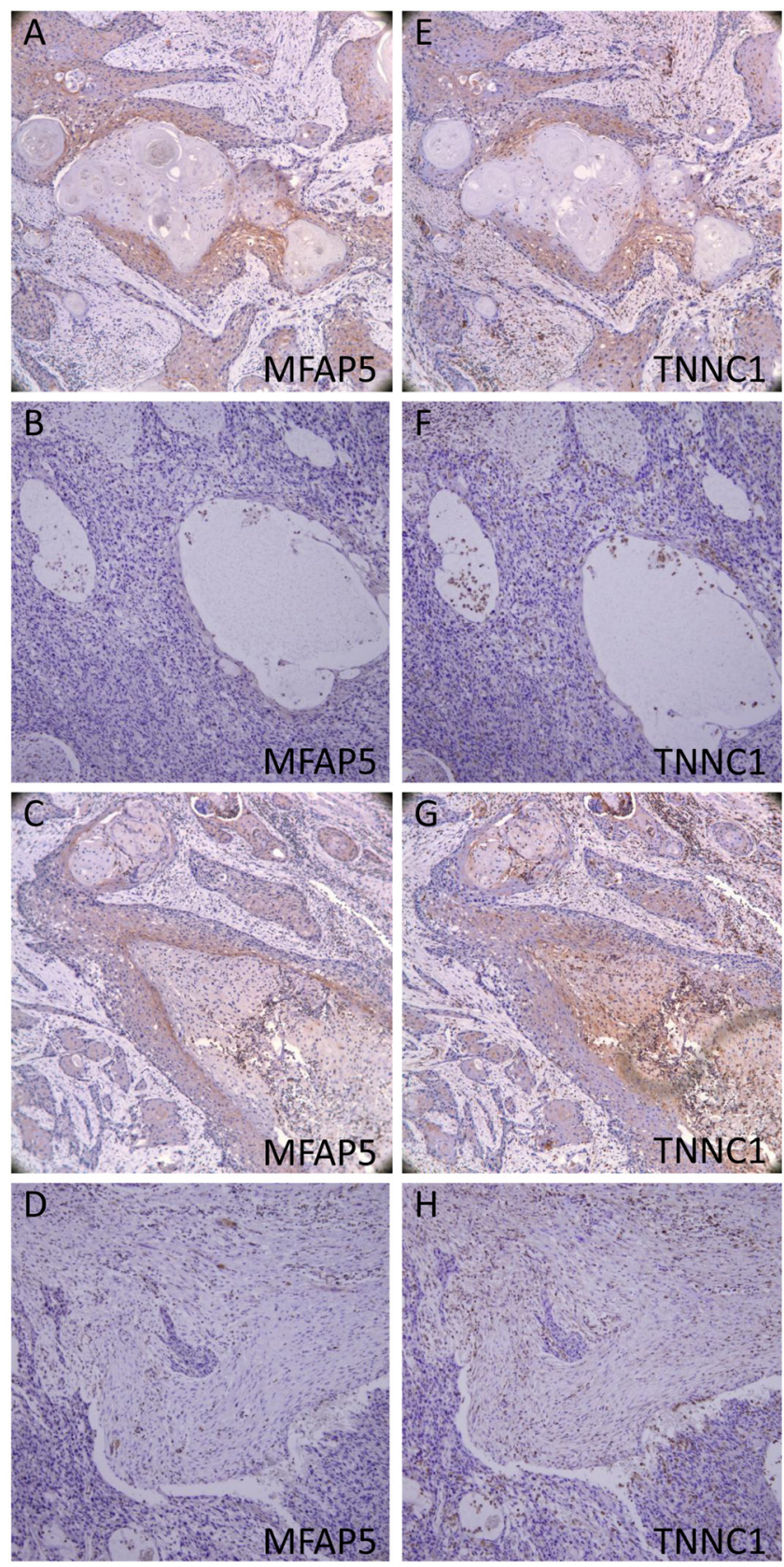

Figure 4: Immunohistochemistry of MFAP5 and TNNC1. A. E. strongly positive; B. F. Weak positive; C. G. Negative cancer cells; D. H. Negative CAFs. 
Table 1: MFAP5 and TNNC1 expression and scores

\begin{tabular}{|c|c|c|c|c|c|c|c|c|c|c|c|c|c|}
\hline \multirow{2}{*}{ Group } & \multirow{2}{*}{$\mathbf{N}$} & \multicolumn{4}{|c|}{ MFAP5 Expression } & \multirow{2}{*}{$\begin{array}{c}\text { MFAP5 } \\
\text { Expression } \\
\text { Rates }\end{array}$} & \multirow{2}{*}{$\begin{array}{c}\text { Mean } \\
\text { MFAP5 } \\
\text { Score }\end{array}$} & \multicolumn{4}{|c|}{ TNNC1 Expression } & \multirow{2}{*}{$\begin{array}{c}\text { TNNC1 } \\
\text { Expression } \\
\text { Rates }\end{array}$} & \multirow{2}{*}{$\begin{array}{c}\text { Mean } \\
\text { TNNC1 } \\
\text { Score }\end{array}$} \\
\hline & & - & + & ++ & +++ & & & - & + & ++ & +++ & & \\
\hline $\mathrm{pN}-$ & 27 & 4 & 8 & 8 & 7 & $25.20 \%$ & 1.556 & 3 & 11 & 11 & 2 & $31.00 \%$ & 1.481 \\
\hline $\begin{array}{l}\mathrm{pN}+(\mathrm{w} / \mathrm{o} \\
\text { recurrence })\end{array}$ & 20 & 0 & 7 & 6 & 7 & $36.25 \%$ & 2.55 & 0 & 5 & 9 & 6 & $44.50 \%$ & 3.45 \\
\hline $\begin{array}{l}\mathrm{pN}+(\text { with } \\
\text { recurrence) }\end{array}$ & 14 & 1 & 4 & 3 & 6 & $37.50 \%$ & 3 & 1 & 1 & 6 & 6 & $55.00 \%$ & 4.429 \\
\hline
\end{tabular}

A

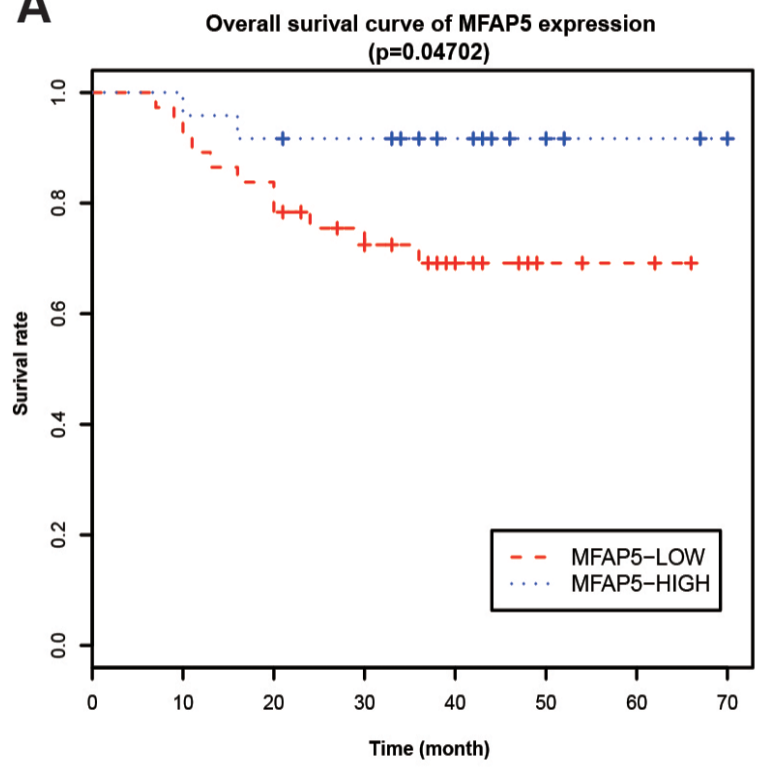

C

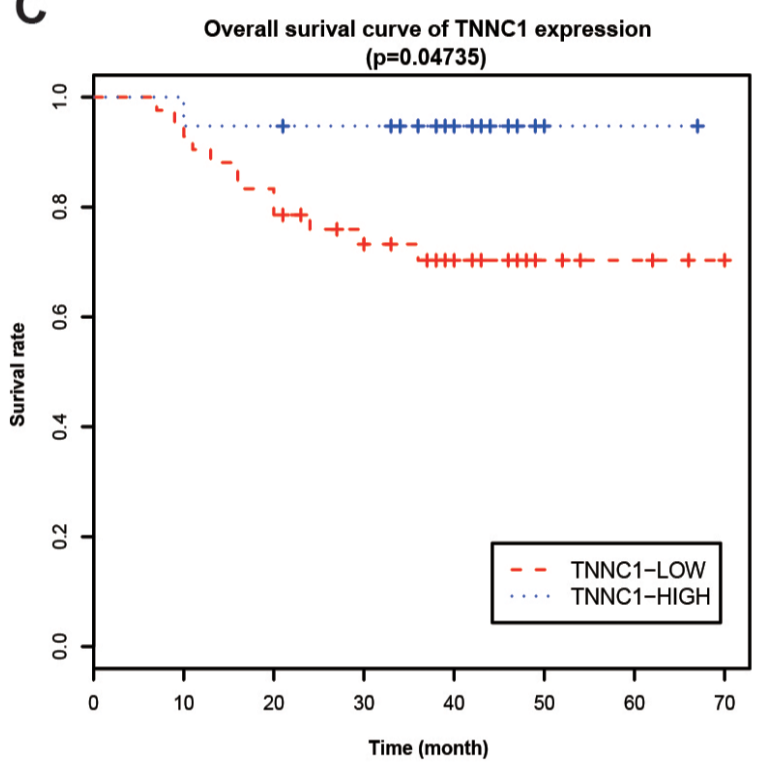

B
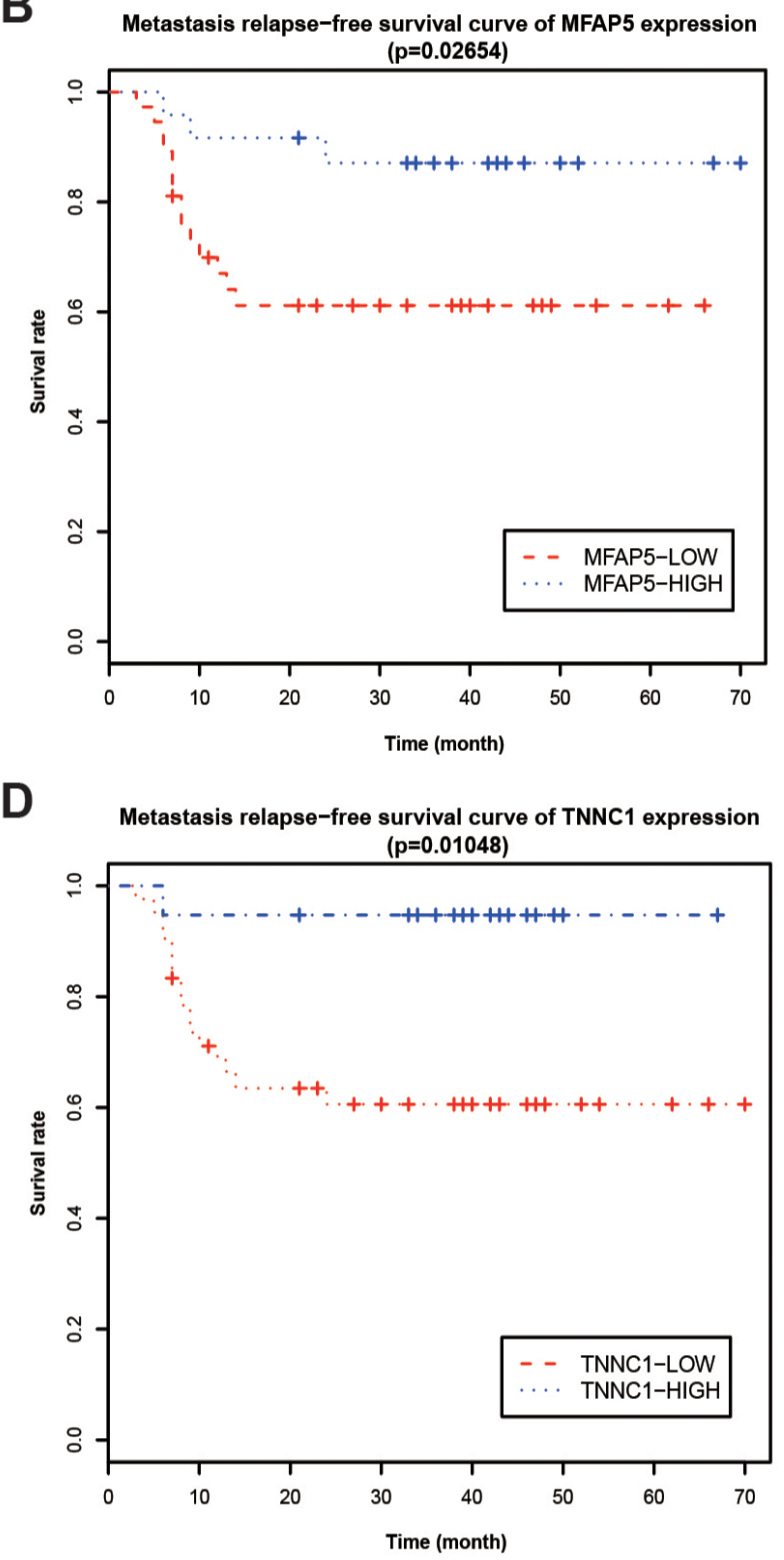

Figure 5: Kaplan-Meier survival analysis relative to MFAP5 and TNNC1 protein levels. A, C. Overall survival rates and B, D. metastasis-free survival rates were analyzed for patients with either low or high MFAP5/TNNC1 expression. 
Table 2: Clinical information and factors related in prognosis

\begin{tabular}{|c|c|c|c|c|}
\hline & Cases & Survival (month) & $95 \% \mathrm{CI}$ & $P$-value \\
\hline Gender & & & & 0.227 \\
\hline Male & 34 & $55.404 \pm 4.195$ & $47.181-63.627$ & \\
\hline Female & 27 & $59.960 \pm 3.330$ & $53.432-66.488$ & \\
\hline Age & & & & 0.037 \\
\hline$\leq 60 \mathrm{y}$ & 36 & $47.857 \pm 3.600$ & $40.802-54.913$ & \\
\hline$>60 y$ & 25 & $65.771 \pm 2.893$ & $60.101-71.441$ & \\
\hline Pathological grades & & & & 0.770 \\
\hline G1 & 13 & $40.092 \pm 2.703$ & $34.794-45.391$ & \\
\hline $\mathrm{G} 2$ & 45 & $57.954 \pm 3.393$ & $51.305-64.604$ & \\
\hline G3 & 3 & $49.333 \pm 13.608$ & $22.661-76.006$ & \\
\hline $\begin{array}{l}\text { Nerve and vascular } \\
\text { invasion }\end{array}$ & & & & 0.032 \\
\hline No & 52 & $60.949 \pm 2.765$ & $55.529-66.369$ & \\
\hline Yes & 9 & $42.333 \pm 9.223$ & $24.256-60.410$ & \\
\hline Tumor status & & & & 0.000 \\
\hline No recurrence & 48 & $64.268 \pm 2.442$ & $59.483-69.054$ & \\
\hline Recurrence & 13 & $30.923 \pm 4.992$ & $21.139-40.707$ & \\
\hline N stage & & & & 0.013 \\
\hline No & 27 & $63.537 \pm 2.397$ & 58.839-68.236 & \\
\hline $\mathrm{N} 1-2$ & 34 & $51.835 \pm 4.514$ & $42.988-60.683$ & \\
\hline Neck status & & & & 0.000 \\
\hline CLNM- & 27 & $63.537 \pm 2.397$ & $58.839-68.236$ & \\
\hline $\begin{array}{l}\mathrm{CLNM}+(\text { none of } \\
\text { recurrence) }\end{array}$ & 20 & $60.850 \pm 4.873$ & $52.300-70.400$ & \\
\hline $\begin{array}{l}\mathrm{CLNM}+(\text { recurrence } \\
\text { after ND) }\end{array}$ & 14 & $31.923 \pm 4.695$ & $22.721-41.125$ & \\
\hline MFAP5 Scores & & & & 0.047 \\
\hline- & 24 & $65.785 \pm 2.902$ & $60.096-71.474$ & \\
\hline+ & 37 & $50.929 \pm 3.840$ & $43.404-58.455$ & \\
\hline TNNC1 Scores & & & & 0.047 \\
\hline- & 19 & $64.000 \pm 2.920$ & $58.277-69.723$ & \\
\hline+ & 42 & $54.619 \pm 3.782$ & $47.206-62.032$ & \\
\hline $\begin{array}{l}\text { MFAP5 and TNNC1 } \\
\text { Scores }\end{array}$ & & & & 0.030 \\
\hline 0 & 14 & $62.929 \pm 3.923$ & $55.239-70.618$ & \\
\hline+- & 15 & $67.571 \pm 2.340$ & $62.985-72.158$ & \\
\hline++ & 32 & $48.516 \pm 4.302$ & $40.084-56.947$ & \\
\hline
\end{tabular}


Table 3: Cox regression of prognostic risk in TSCC patients

\begin{tabular}{lcccc}
\hline \multirow{2}{*}{ Factor } & \multicolumn{2}{c}{ Cox regression } & \multicolumn{2}{c}{ Cox regression } \\
\cline { 2 - 5 } & \multicolumn{1}{c}{ Univariate } & $\boldsymbol{p}$ & Multivariate & $\boldsymbol{p}$ \\
\hline $\begin{array}{l}\text { Age }(\leq 60 \text { years }) \\
\begin{array}{l}\text { Nerve vascular } \\
\text { invasion }\end{array}\end{array}$ & $\begin{array}{l}\text { 4.319(0.957-19.499) } \\
\text { Co-expression of }\end{array}$ & 0.057 & $4.562(0.994-20.944)$ & 0.050 \\
MFAP5 and TNNC1 & $5.969(1.320-26.991)$ & 0.044 & $5.107(1.445-18.054)$ & 0.011 \\
\hline
\end{tabular}

Table 4: Correlation between MFAP5 and TNNC1 expression

\begin{tabular}{|c|c|c|c|c|c|c|c|}
\hline & CLNM- & $\begin{array}{c}\text { CLNM+ } \\
\text { (w/o recur) }\end{array}$ & $\begin{array}{c}\text { CLNM+ } \\
\text { (with recur) }\end{array}$ & $P$ & CLNM- & CLNM+ & $P$ \\
\hline MFAP5- & 17 & 5 & 2 & 0.006 & 17 & 7 & 0.002 \\
\hline MFAP5+ & 11 & 15 & 11 & & 11 & 26 & \\
\hline TNNC1- & 14 & 5 & 0 & 0.004 & 14 & 5 & 0.003 \\
\hline TNNC1+ & 14 & 15 & 13 & & 14 & 28 & \\
\hline MFAP5-TNNC1- & 11 & 3 & 0 & 0.006 & 11 & 3 & 0.002 \\
\hline $\begin{array}{l}\text { MFAP5+TNNC1-/ } \\
\text { MFAP-TNNC1+ }\end{array}$ & 9 & 4 & 2 & & 9 & 6 & \\
\hline MFAP5+TNNC1+ & 8 & 13 & 11 & & 8 & 24 & \\
\hline
\end{tabular}

CLNM = cervical lymphatic neck metastasis

in EMT process, were significantly changed in TSCC. MFAP5 and TNNC1 showed accordance between realtime PCR and Affymetrix microarray, which were further validated by immunochemistry using specimens from our clinical trial.

MFAP5 (also known as microfibril-associated glycoprotein 2, MAGP2) is a multifunctional protein that plays an important role in elastic microfibril assembly and modulating endothelial cell behavior, and thus it is considered as a novel modulator in cell survival [17]. MFAP5 expression was increased in head, neck, pancreatic, lung, and ovarian cancers [18-21]. However, the role of MFAP5 in these cancers remains to be elucidated. MFAP5 was an independent predictor of survival in advanced ovarian cancer, and could promote tumor proliferation and endothelial cell motility through $\alpha \beta \mathrm{V}_{3}$ integrin mediated signaling, providing a potential mechanistic link between MFAP5 and angiogenesis as well as patient survival $[22,23]$. In this study, MFAP5 had a higher correlation with occult cervical metastasis than other genes examined, suggesting the potential role of MFAP5 in the diagnosis of occult cervical metastasis. In addition, the mRNA and protein levels of MFAP5 were significantly elevated in patients with poor prognosis, thus indicating that MFAP5 could be an independent prognostic marker for TSCC and its occult cervical metastasis.
TNNC1 is known as a $\mathrm{Ca}^{2+}$-binding subunit that can facilitate the relationship between actin and myosin in muscle cells. However, in non-muscle cells, TNNC1 may act as a regulatory protein for cellular locomotion, cytoplasmic streaming and cytokinesis, rather than as a structural protein [24]. TNNC1 was over-expressed in ovarian cancer cells, and elevated TNNC1 expression regulated epithelial cancer cell motility and invasion potential via cytoskeleton reorganization $[25,26]$. TNNC1 was an effector protein of MFAP5 in stomata, which promoted cell motility and invasion potential via tumor-stroma crosstalk and subsequently affected clinical outcomes [21]. However, the relationship between MFAP5 and TNNC1 in oral cancers remains unclear. The TNNC1 expression was altered in oral cancer. Our results showed that MFAP5 and TNNC1 expressions were associated with CLNM and cervical lymphatic recurrence. A majority of patients with CLNM were positive for MFAP5 (11/13) and TNNC1 (15/15). Thus, TNNC1 appeared to be more sensitive than MFAP5 in predicting the prognosis of TSCC and its occult cervical lymphatic metastasis. However, further studies are needed to validate our results due to limited sample size and detection methods used.

In conclusion, MFAP5 and TNNC1 could be potential markers for predicting occult cervical lymphatic metastasis and prognosis of oral tongue carcinoma. 


\section{MATERIALS AND METHODS}

\section{Sample selection}

Fresh tumor and normal tissue specimens were collected from 12 patients underwent surgical resection for TSCC and selective neck dissection at the Department of Oral \& Maxillofacial-Head and Neck Oncology, Shanghai Ninth People's Hospital, School of Medicine, Shanghai Jiaotong University, from July 2013 to August 2014 following the guidelines established by our university. All patients gave their informed written consent to participate in this study. Tumor specimens for PCR and immunochemistry were selected by computer-generated random numbers from 171 patients enrolled in a previous prospective randomized trial [27]. Adjuvant treatment was given after operation. In each patient, TSCC samples were collected near the forward edge of the tumor instead of the necrotic center, and then immediately snap frozen and stored in liquid nitrogen until use. Histologically normal mucosa was obtained $3 \mathrm{~cm}$ away from the tumor in all cases.

Tumors were staged as $\mathrm{T}_{2}$ according to the AJCC/ UICC TNM classification (7th edition). In this study, node-positive refers to the presence of positive CLNM, while node negative refers to the absence of positive CLNM for at least 18 months after operation based on histological diagnosis after neck dissection.

\section{Transcriptome microarray and functional analysis}

Tumor and normal tissues obtained from 12 patients were used for oligonucleotide microarray analysis. Twenty (TN paired) patients had primary tumor samples and matched normal mucosa available for analysis, which were used for oligonucleotide microarray analysis. Total RNA was extracted from snap-frozen tissue samples following the manufacturer's protocol and re-purified by RNA easy Mini-spin column (Qiagen). The cDNA was used for in vitro transcription amplification in the presence of biotinylated nucleotides. The labeled cRNA was fragmented and then hybridized against the GeneChip Human Transcriptome Array 2.0 oligonucleotide arrays (Affymetrix, Santa Clara, CA). The arrays were scanned using a Hewlett Packard confocal laser scanner and analyzed with MicroArray Suite 5.0 (Affymetrix). Differentially expressed genes were further analyzed with Gene Ontology (Go) and Kyoto Encyclopedia of Genes and Genomes (KEGG) for their functions and related pathways.

\section{RNA preparation and real-time RT-PCR}

RT-PCR was performed for the expression of MFAP5, MGP, FGFBP1, FBXO32 and TNNC1 in a larger cohort of 32 patients. Two $\mu \mathrm{g}$ of total RNA was reverse transcribed with MultiScribe ${ }^{\mathrm{TM}}$ Reverse Transcriptase (Applied Biosystems, Inc., Foster City, CA). Gene specific primers were designed using the Primer3 Program. The PCR primer sets (in 5'-3' direction) were as follows: MFAP5 forward: GCCAGCCAAAGTAGGAACAG, MFAP5 backward: AGCAAGAAACAGCAGCACCT; MGP forward: CCCTCTCAACTGCTCTGGTT, MGP backward: CAGGCTCTTCATGGTTTCGT; FGFBP1 forward: CCCTGCTCTCCTTCCTCCTA, FGFBP1 backward: GTGTTGCCCAGAGTGTCCTT; FBXO32 forward: AGCGGATGTTCATTCTCCAC, FBXO32 backward: AAATGCCCAGCAGACAAAGT; TNNC1 forward: CAGCAAAGGGAAATCTGAGG, TNNC1 backward: TGATGGTCTCGCCTGTAGC.

\section{Immunohistochemistry}

The expression levels of MFAP5 and TNNC1 proteins in TSCC were further examined by immunohistochemistry. The TSCC tissues were embedded and cut into $5-\mu \mathrm{m}$ sections. Then, the sections were stained by monoclonal antibody to TNNC1 (1: 100, WH0007134M1, Sigma-Aldrich) and polyclonal antibody to MFAP5 (1: 100, HPA010553, Sigma-Aldrich), and examined by two independent pathologists in our hospital. MFAP5 and TNNC1 expressions were examined using a scoring method. The mean percentage of positive tumor cells was determined by examining 500 cells in at least 5 sections at $40 \times 10$ magnification. Cells were assigned to one of the following four classes according to the percentage of positive cells (PP): 0$) \leq 24 \%$; 1) $25-49 \%$; 2) $50-74 \%$; and 3) $75-100 \%$. The intensity of MFAP5 and TNNC1 staining (SI) was scored as: 0) no, -; 1) weak, +; 2) moderate, ++; and 3) intense, +++. The final immunoreactive score was calculated by the following formula: IRS $=\mathrm{SI} \times \mathrm{PP}$. A score higher than 0 indicates positive expression, whereas a score lower than 0 indicates negative expression. The stained tissues were scored by researchers who were blind to the patients.

\section{Statistical analysis}

The Kaplan-Meier method was used to estimate metastasis-free rates using SPSS version 13.0 (IBM, Armonk, NY), and the $\chi^{2}$ analysis and Mantel-Haenszel log-rank test were used to calculate the statistical significance (P-value) of the difference between the curves. $P<0.05$ was considered as statistically significant. The follow-up period was defined as the interval from the time of biopsy or dissection for pathological diagnosis to the final follow-up date of January 2016. The neck nodal metastasis was defined as positive cervical lymph node when the patient underwent neck dissection in one stage or neck metastasis during the wait-and-see period. The overall and disease-free survival was determined by using the Kaplan-Meier method and the Log-rank test. 


\section{ACKNOWLEDGMENTS}

This work was partially supported by National Natural Science Foundation of China (grant nos. 81602367 and 81602370), Research Grants (15411950300 and 13ZR1457100) from Science and Technology Commission of Shanghai Municipality and Shanghai Summit \& Plateau Disciplines.

\section{CONFLICTS OF INTEREST}

The authors declare no conflicts of interest.

\section{REFERENCES}

1. Jemal A, Bray F, Center MM, Ferlay J, Ward E, Forman D. Global cancer statistics. CA: a cancer journal for clinicians. 2011; 61:69-90.

2. Ren $\mathrm{ZH}, \mathrm{Xu}$ JL, Li B, Fan TF, Ji T, Zhang CP. Elective versus therapeutic neck dissection in node-negative oral cancer: Evidence from five randomized controlled trials. Oral Oncol. 2015; 51:976-981.

3. Ren ZH, Wu HJ, Wang K, Zhang S, Tan HY, Gong ZJ. Anterolateral thigh myocutaneous flaps as the preferred flaps for reconstruction of oral and maxillofacial defects. J Craniomaxillofac Surg. 2014; 42:1583-1589.

4. Ren ZH, Wu HJ, Tan HY, Wang K, Zhang S. Transfer of anterolateral thigh flaps in elderly oral cancer patients: complications in oral and maxillofacial reconstruction. J Oral Maxillofac Surg. 2015; 73:534-540.

5. Huang SF, Chang JT, Liao CT, Kang CJ, Lin CY, Fan KH, Wang HM, Chen IH. The role of elective neck dissection in early stage buccal cancer. Laryngoscope. 2015; 125:128-133.

6. Ren ZH, Xu JL, Fan TF, Ji T, Wu HJ, Zhang CP. The Harmonic Scalpel versus Conventional Hemostasis for Neck Dissection: A Meta-Analysis of the Randomized Controlled Trials. PLoS One. 2015; 10:e0132476.

7. Yuen AP, Ho CM, Chow TL, Tang LC, Cheung WY, Ng RW, Wei WI, Kong CK, Book KS, Yuen WC, Lam AK, Yuen NW, Trendell-Smith NJ, et al. Prospective randomized study of selective neck dissection versus observation for N0 neck of early tongue carcinoma. Head Neck. 2009; 31:765-772.

8. Fasunla AJ, Greene BH, Timmesfeld N, Wiegand S, Werner JA, Sesterhenn AM. A meta-analysis of the randomized controlled trials on elective neck dissection versus therapeutic neck dissection in oral cavity cancers with clinically node-negative neck. Oral Oncol. 2011; 47:320-324.

9. D'Cruz AK, Vaish R, Kapre N, Dandekar M, Gupta S, Hawaldar R, Agarwal JP, Pantvaidya G, Chaukar D, Deshmukh A, Kane S, Arya S, Ghosh-Laskar S, et al. Elective versus Therapeutic Neck Dissection in NodeNegative Oral Cancer. N Engl J Med. 2015; 373:521-529.
10. Estilo CL, P Oc, Talbot S, Socci ND, Carlson DL, Ghossein R, Williams T, Yonekawa Y, Ramanathan Y, Boyle JO, Kraus DH, Patel S, Shaha AR, et al. Oral tongue cancer gene expression profiling: Identification of novel potential prognosticators by oligonucleotide microarray analysis. BMC Cancer. 2009; 9:11.

11. Alevizos I, Mahadevappa M, Zhang X, Ohyama H, Kohno Y, Posner M, Gallagher GT, Varvares M, Cohen D, Kim D, Kent R, Donoff RB, Todd R. Oral cancer in vivo gene expression profiling assisted by laser capture microdissection and microarray analysis. Oncogene. 2001; 20:6196-6204.

12. Belbin TJ, Singh B, Barber I, Socci N, Wenig B, Smith R, Prystowsky MB, Childs G. Molecular classification of head and neck squamous cell carcinoma using cDNA microarrays. Cancer Res. 2002; 62:1184-1190.

13. Freier K, Joos S, Flechtenmacher C, Devens F, Benner A, Bosch FX, Lichter P, Hofele C. Tissue microarray analysis reveals site-specific prevalence of oncogene amplifications in head and neck squamous cell carcinoma. Cancer Res. 2003; 63:1179-1182.

14. O'Donnell RK, Kupferman M, Wei SJ, Singhal S, Weber R, O'Malley B, Cheng Y, Putt M, Feldman M, Ziober B, Muschel RJ. Gene expression signature predicts lymphatic metastasis in squamous cell carcinoma of the oral cavity. Oncogene. 2005; 24:1244-1251.

15. Chong CE, Lim KP, Gan CP, Marsh CA, Zain RB, Abraham MT, Prime SS, Teo SH, Silvio Gutkind J, Patel V, Cheong SC. Over-expression of MAGED4B increases cell migration and growth in oral squamous cell carcinoma and is associated with poor disease outcome. Cancer Lett. 2012; 321:18-26.

16. Ishige S, Kasamatsu A, Ogoshi K, Saito Y, Usukura K, Yokoe H, Kouzu Y, Koike H, Sakamoto Y, Ogawara K, Shiiba M, Tanzawa H, Uzawa K. Decreased expression of kallikrein-related peptidase 13: possible contribution to metastasis of human oral cancer. Mol Carcinog. 2014; 53:557-565.

17. Vaittinen M, Kolehmainen M, Ryden M, Eskelinen M, Wabitsch M, Pihlajamaki J, Uusitupa M, Pulkkinen L. MFAP5 is related to obesity-associated adipose tissue and extracellular matrix remodeling and inflammation. Obesity (Silver Spring). 2015; 23:1371-1378.

18. Ceder R, Haig Y, Merne M, Hansson A, Zheng X, Roberg K, Nees M, Iljin K, Bloor BK, Morgan PR, Fadeel B, Grafstrom RC. Differentiation-promoting culture of competent and noncompetent keratinocytes identifies biomarkers for head and neck cancer. Am J Pathol. 2012; 180:457-472.

19. Bild AH, Yao G, Chang JT, Wang Q, Potti A, Chasse D, Joshi MB, Harpole D, Lancaster JM, Berchuck A, Olson JA, Jr., Marks JR, Dressman HK, et al. Oncogenic pathway signatures in human cancers as a guide to targeted therapies. Nature. 2006; 439:353-357.

20. Brandsma CA, van den Berge M, Postma DS, Jonker MR, Brouwer S, Pare PD, Sin DD, Bosse Y, Laviolette M. 
Karjalainen J, Fehrmann RS, Nickle DC, Hao K. A large lung gene expression study identifying fibulin- 5 as a novel player in tissue repair in COPD. Thorax. 2015; 70:21-32.

21. Leung CS, Yeung TL, Yip KP, Pradeep S, Balasubramanian L, Liu J, Wong KK, Mangala LS, Armaiz-Pena GN, LopezBerestein G, Sood AK, Birrer MJ, Mok SC. Calciumdependent FAK/CREB/TNNC1 signalling mediates the effect of stromal MFAP5 on ovarian cancer metastatic potential. Nat Commun. 2014; 5:5092.

22. Mok SC, Bonome T, Vathipadiekal V, Bell A, Johnson ME, Wong KK, Park DC, Hao K, Yip DK, Donninger H, Ozbun L, Samimi G, Brady J, et al. A gene signature predictive for outcome in advanced ovarian cancer identifies a survival factor: microfibril-associated glycoprotein 2. Cancer Cell. 2009; 16:521-532.

23. Spivey KA, Banyard J. A prognostic gene signature in advanced ovarian cancer reveals a microfibril-associated protein (MAGP2) as a promoter of tumor cell survival and angiogenesis. Cell Adh Migr. 2010; 4:169-171.
24. Pinto JR, Siegfried JD, Parvatiyar MS, Li D, Norton N, Jones MA, Liang J, Potter JD, Hershberger RE. Functional characterization of TNNC1 rare variants identified in dilated cardiomyopathy. J Biol Chem. 2011; 286:34404-34412.

25. Wang WZ, Li T, Shi LJ, Yan XR, Pan YL, Wu XS. Screening of differentially-expressed genes in the muscles of rabbit breeds with expression profile chip. Genet Mol Res. 2015; 14:8038-8045.

26. Berkman LF, Liu SY, Hammer L, Moen P, Klein LC, Kelly E, Fay M, Davis K, Durham M, Karuntzos G, Buxton OM. Work-family conflict, cardiometabolic risk, and sleep duration in nursing employees. Journal of occupational health psychology. 2015; 20:420-433.

27. Wu K, Yang X, Li L, Ruan M, Liu W, Lu W, Zhang C, Li S. Neurovascular Invasion and Histological Grade Serve as the Risk Factors of Cervical Lymph Node Metastases in Early Tongue Squamous Cell Carcinoma. Mol Neurobiol. 2016;53:2920-2926. 